\title{
Mechanistic Implications of Zinc(II) Ions on the Degradation of Phenol by the Fenton Reaction
}

\author{
Leidi Cecilia Friedrich, ${ }^{*, a}$ Maria Anita Mendes, ${ }^{b}$ Volnir Oliveira Silva, ${ }^{a}$ \\ Carmem Lúcia P. S. Zanta, ${ }^{c}$ Amilcar Machulek Jr. ${ }^{d}$ and Frank Herbert Quina ${ }^{a}$
}

${ }^{a}$ Instituto de Química, Universidade de São Paulo, CP 26077, 05513-970 São Paulo-SP, Brazil

${ }^{b}$ Departamento de Engenharia Química, Escola Politécnica, Universidade de São Paulo, 05508-000 São Paulo-SP, Brazil

'Instituto de Química e Biotecnologia, Universidade Federal de Alagoas, Campus A. C. Simões, 57072-970 Maceió-AL, Brazil

${ }^{d}$ Departamento de Química, Universidade Federal de Mato Grosso do Sul, 79074-760 Campo Grande-MS, Brazil

\begin{abstract}
Um estudo da interferência de íons $\mathrm{Zn}^{2+}$ na reação de Fenton $\left(\mathrm{Fe}^{2+} / \mathrm{Fe}^{3+}+\mathrm{H}_{2} \mathrm{O}_{2}\right)$ na degradação de fenol é relatado. Um dos intermediários formados inicialmente na reação, catecol, pode reduzir $\mathrm{Fe}^{3+} \mathrm{a} \mathrm{Fe}^{2+}$, e na presença de $\mathrm{H}_{2} \mathrm{O}_{2}$ inicia um ciclo redox catalítico. Nas etapas iniciais da reação, este ciclo mediado por catecol torna-se a principal via de degradação térmica de fenol e seus produtos de oxidação. A adição de íons $\mathrm{Zn}^{2+}$ aumenta o tempo de persistência do catecol, provavelmente por estabilização do radical semiquinona via complexação.
\end{abstract}

A study of the interference of $\mathrm{Zn}^{2+}$ ions on phenol degradation by Fenton reaction $\left(\mathrm{Fe}^{2+} / \mathrm{Fe}^{3+}+\mathrm{H}_{2} \mathrm{O}_{2}\right)$ is reported. One of the first intermediates formed in the reaction, catechol, can reduce $\mathrm{Fe}^{3+}$ to $\mathrm{Fe}^{2+}$ and, in the presence of $\mathrm{H}_{2} \mathrm{O}_{2}$ initiates an efficient catalytic redox cycle. In the initial stages of the reaction, this catechol-mediated cycle becomes the principal route of thermal degradation of phenol and its oxidation products. The $\mathrm{Zn}^{2+}$ ion addition enhances the persistence time of catechol, probably by stabilization of the corresponding semiquinone radical via complexation.

Keywords: phenol, $\mathrm{Zn}^{2+}$ ions, Fenton reaction

\section{Introduction}

More than a century ago, Fenton ${ }^{1}$ showed that a mixture of $\mathrm{H}_{2} \mathrm{O}_{2}$ and $\mathrm{Fe}^{2+}$ in acidic medium had very strong oxidizing properties. Fenton reaction is an important source of hydroxyl radicals, ${ }^{1-6}$ which oxidize organic substances, ${ }^{1}$ in many cases to carbon dioxide and water.

A means of accelerating the rate of the Fenton reaction is via the use of phenolic compounds, especially dihydroxybenzene (DHBs), which have the ability to reduce $\mathrm{Fe}^{3+}$ to $\mathrm{Fe}^{2+}$. Hamilton et al. ${ }^{7}$ were the first to report that catalytic amounts of dihydroxybenzene (catechol or 1,4-hydroquinone), the primary initial intermediates in phenol degradation, ${ }^{8,9}$ were able to increase the degradation

*e-mail: leidi@iq.usp.br rate of aromatic compounds in Fenton reactions. The same effect is observed when catechol is added to the reaction medium. $\mathrm{Fe}^{2+}$ forms a 1:1 complex with catechol that decomposes the ortho-semiquinone radical and $\mathrm{Fe}^{3+}$ ion. The semiquinone radical is unstable and is oxidized by another $\mathrm{Fe}^{3+}$ ion, leading to 1,2-benzoquinone. The 1,2-benzoquinone formed can interact with the superoxide ion to reform the semiquinone radical and molecular oxygen. This redox cycle, illustrated in Scheme 1, represents the Hamilton catalytic cycle.

In the technique of EPR (electron paramagnetic resonance), diamagnetic metal ions are used to complex semiquinone free radicals, increasing the kinetic stability of these radicals. ${ }^{10}$ Thus, for example, Yamasaki and Grace $^{11}$ employed zinc ions as stabilizing agents to detect semiquinone radicals by EPR in the coupled system 


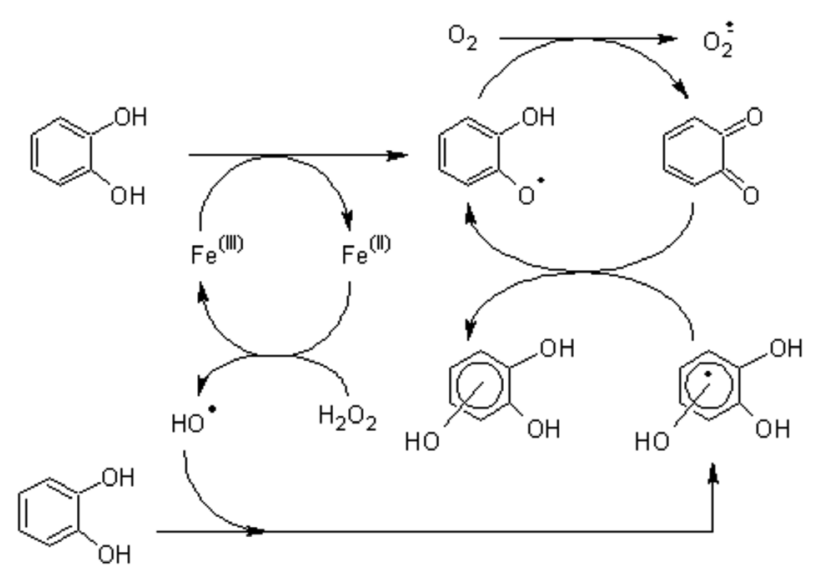

Scheme 1. Hamilton catalytic cycle for catechol (adapted from ref. 5). ${ }^{8}$

peroxidase/phenolic. This work aimed to study the mechanistic implications of zinc ions in the Fenton reaction using phenol as model compound.

\section{Experimental}

\section{Materials}

Ferrous sulfate heptahydrate $\left(\mathrm{FeSO}_{4} \cdot 7 \mathrm{H}_{2} \mathrm{O}\right.$, Synth), zinc sulfate $\left(\mathrm{ZnSO}_{4}\right.$, Synth), hydrogen peroxide $\left(\mathrm{H}_{2} \mathrm{O}_{2}\right.$, $30 \%$, Synth), sulfuric acid $\left(\mathrm{H}_{2} \mathrm{SO}_{4}\right.$, Synth), sodium hydroxide (NaOH, Merck), phenol (Aldrich), catechol (Acros), hydroquinone (Aldrich), oxalic acid (Aldrich) and acetonitrile (JT Baker) (all reagent grade or superior) were used as received.

\section{General procedure for degradation experiments}

The solutions of phenol were prepared by directly dissolving the desired amount of phenol in aqueous solution. The reactor used for the degradation of phenol was a batch reactor with an internal volume of $1.0 \mathrm{~L}$, protected from incident light in order to minimize the influence of photochemical reactions. The solution temperature was controlled at $30^{\circ} \mathrm{C}$ by using a thermostatic bath and magnetic stirring.

Initially, a solution containing $10 \mathrm{mmol} \mathrm{L} \mathrm{L}^{-1}$ phenol, $0.5 \mathrm{mmol} \mathrm{L}^{-1} \mathrm{Fe}^{2+}$ and different concentrations of $\mathrm{Zn}^{2+}$ at $\mathrm{pH} 3.0$ was added to the reactor. Aqueous hydrogen peroxide was slowly added $\left(3.33 \mathrm{mmol} \mathrm{L}^{-1} \mathrm{~min}^{-1}\right)$, with the aid of a peristaltic pump during the first $60 \mathrm{~min}$ of the reaction to minimize the formation of the hydroperoxide radical. At selected time intervals, $5 \mathrm{~mL}$ of sample solution were collected and 2 drops of a solution of $2.0 \mathrm{mmol} \mathrm{L}^{-1}$ $\mathrm{NaOH}$ immediately added, raising $\mathrm{pH}$ to ca. 12. The increase in $\mathrm{pH}$ precipitated $\mathrm{Fe}^{3+}$, stopping the reaction. After filtration, the sample was reacidified to a $\mathrm{pH}$ around 3.0 to maintain the same conditions as in the reactor and total organic carbon (TOC) was analyzed with a Shimadzu Model TOC-5000A analyzer.

General procedure for high-performance liquid chromatography (hplc) analysis

Phenol and the main degradation products (hydroxyaromatics and aliphatic acids) were identified and quantified by high performance liquid chromatography (for hydroxyaromatics, a Shimadzu 2010A LC-MS with ionization in the APCI negative mode, and for aliphatic acids, a Shimazdu 20AD HPLC) using standard compounds for identification and calibration.

For the determination of aromatic intermediates, a Shim-pack $\mathrm{C}_{18}$ reverse phase column $(5 \mu \mathrm{m}, 4.6 \times 150 \mathrm{~mm})$ was used with detection at $270 \mathrm{~nm}$. The mobile phase consisted of an aqueous solution containing $0.2 \%$ acetic acid (A) and acetonitrile containing $0.2 \%$ acetic acid (B). For $3 \mathrm{~min}$, the mobile phase (flow rate $0.7 \mathrm{~mL} \mathrm{~min}^{-1}$ ) was $18 \% \mathrm{~B}: 82 \% \mathrm{~A}$, followed by a gradient of $18-58 \%$ B over $10 \mathrm{~min}$ and completing the analysis by reverting for $1 \mathrm{~min}$ to $18 \% \mathrm{~B}: 82 \% \mathrm{~A}$. The main intermediates of the phenol degradation reaction were identified by their retention times and by their molecular masses. The retention times were $16.3 \mathrm{~min}$ for phenol, $13.5 \mathrm{~min}$ for catechol and $12.5 \mathrm{~min}$ for hydroquinone.

To determine the intermediate acids, a Hamilton PRP Brand-X300 ion exchange column was used with UV detection at $220 \mathrm{~nm}$. The mobile phase consisted of an aqueous solution of $\mathrm{H}_{2} \mathrm{SO}_{4}(\mathrm{pH} 2.00 \pm 0.02)$, at a flow rate of $1 \mathrm{~mL} \mathrm{~min}{ }^{-1}$ with the column temperature maintained at $30^{\circ} \mathrm{C}$. Before being injected onto the ion exchange column, the samples were filtered through a $\mathrm{C}_{18}$ cartridge previously activated with methanol. This step removed the remaining aromatic compounds, this is necessary since these compounds are strongly retained on the ion exchange column, resulting in broad bands that hamper analysis. ${ }^{12}$

\section{Results and Discussion}

The efficiency of the Fenton reaction for the mineralization of phenol (reduction of the value of TOC) was determined as a function of time, as shown in Figure 1. The influence of the concentration of zinc ions on the oxidation of phenol was analyzed by fixing the concentrations of $\mathrm{H}_{2} \mathrm{O}_{2}$ and $\mathrm{Fe}^{2+}$ and varying the concentration of $\mathrm{Zn}^{2+}$.

In the presence of $\mathrm{Fe}^{2+}$ ion, the system shows a high degradation rate, the beginning of the reaction reaching a 


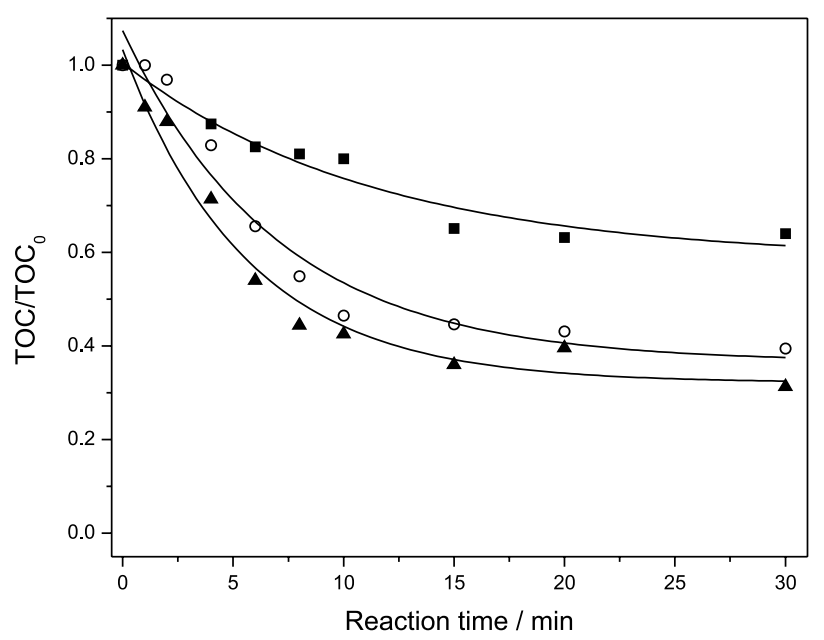

Figure 1. Effect of zinc ions on the degradation of phenol $\left(10 \mathrm{mmol} \mathrm{L}^{-1}\right.$ initial $)$ by the Fenton reaction. Experimental conditions: $\left[\mathrm{Fe}^{2+}\right]=0.5 \mathrm{mmol} \mathrm{L}-1$, $\left[\mathrm{H}_{2} \mathrm{O}_{2}\right]=200 \mathrm{mmol} \mathrm{L}^{-1}, \mathrm{~T}=30^{\circ} \mathrm{C}$ and $\mathrm{pH}_{\text {initial }} 3.0$; [ $\left.\mathrm{Zn}^{2+}\right]$ : absence $(\boldsymbol{\square})$, $5 \mathrm{mmol} \mathrm{L}^{-1} \mathrm{Zn}^{2+}(\mathrm{O})$ and $50 \mathrm{mmol} \mathrm{L}^{-1} \mathrm{Zn}^{2+}(\mathbf{\Delta})$.

maximum of $25 \%$ degraded after $15 \mathrm{~min}$, and then the TOC value remains constant. Joining the two reaction, Fenton and zinc, the degradation reaches $70 \%$ reduction at the end of the reaction (Figure 1). In both conditions, the mineralization was not completed due to the formation of intermediate compounds that interfere with the Fenton reaction.

Figure 2 shows that phenol was totally degraded in 10 min of reaction, both in the presence and absence of zinc ions. $\mathrm{Zn}^{2+}$ did not significantly influence the phenol disappearance rate, suggesting that zinc ions do not interfere with the formation of $\mathrm{HO}^{\bullet}$ radicals. In contrast, the analysis of the intermediates initially formed in the degradation of phenol showed an increase in the persistence time of catechol in the reaction system in the presence of $\mathrm{Zn}^{2+}$ (Figure 3). In addition, as shown in Figure 4, there is

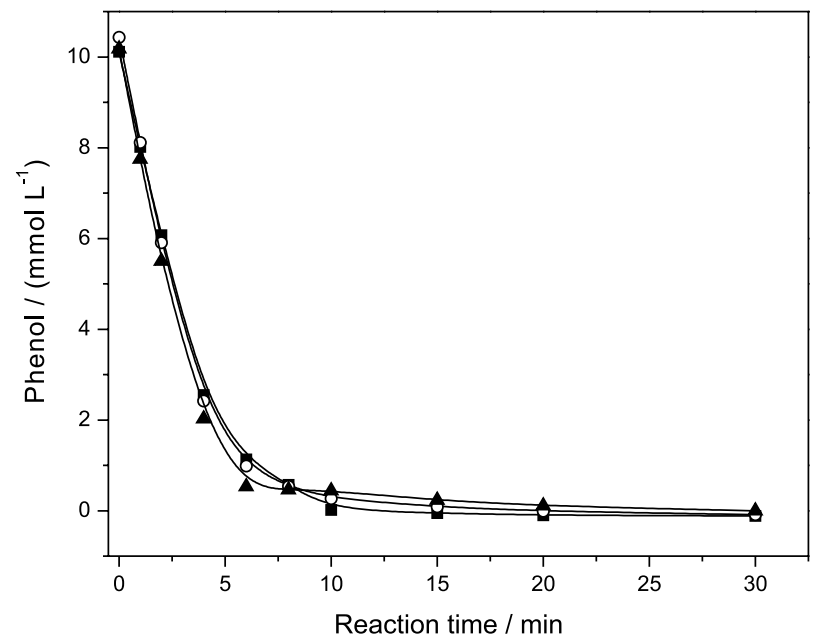

Figure 2. Degradation of phenol as a function of the concentration of $\mathrm{Zn}^{2+}$ added to the system. Experimental conditions: $\left[\mathrm{Fe}^{2+}\right]=0.5 \mathrm{mmol} \mathrm{L}^{-1}$, $\left[\mathrm{H}_{2} \mathrm{O}_{2}\right]=200 \mathrm{mmol} \mathrm{L}^{-1}, \mathrm{~T}=30^{\circ} \mathrm{C}$ and $\mathrm{pH}_{\text {initial }} 3.0 ;\left[\mathrm{Zn}^{2+}\right]$ : absence $(\mathbf{\square})$, $5 \mathrm{mmol} \mathrm{L}^{-1}(\mathrm{O})$ and $50 \mathrm{mmol} \mathrm{L}^{-1}(\mathbf{\Delta})$.

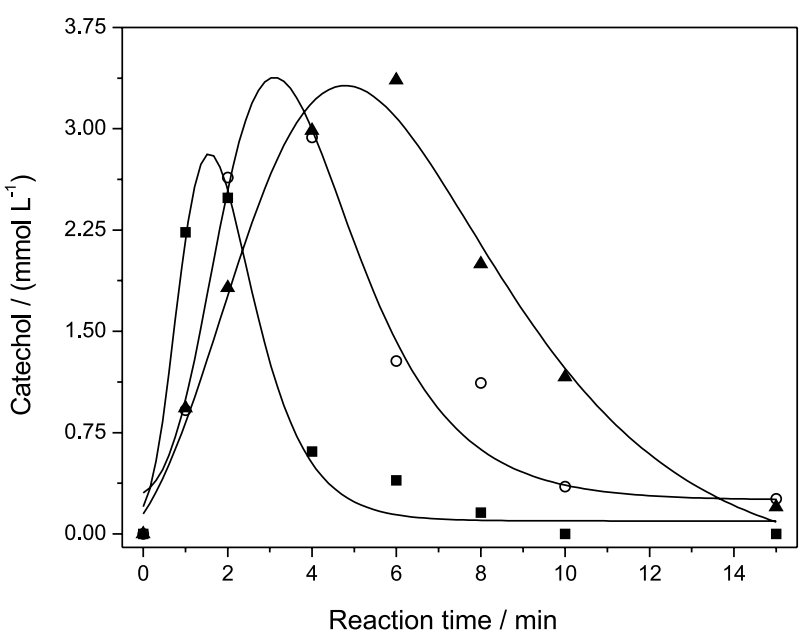

Figure 3. Formation and consumption of catechol as a function of the concentration of $\mathrm{Zn}^{2+}$ added to the system. Experimental conditions: $\left[\mathrm{Fe}^{2+}\right]=0.5 \mathrm{mmol} \mathrm{L}^{-1},\left[\mathrm{H}_{2} \mathrm{O}_{2}\right]=200 \mathrm{mmol} \mathrm{L}^{-1}, \mathrm{~T}=30^{\circ} \mathrm{C}$ and $\mathrm{pH}_{\text {initial }} 3.0$; $\left[\mathrm{Zn}^{2+}\right]$ : absence $(\boldsymbol{\square}), 2 \mathrm{mmol} \mathrm{L}^{-1}(\bigcirc)$ and $5 \mathrm{mmol} \mathrm{L}^{-1}(\boldsymbol{\Delta})$.

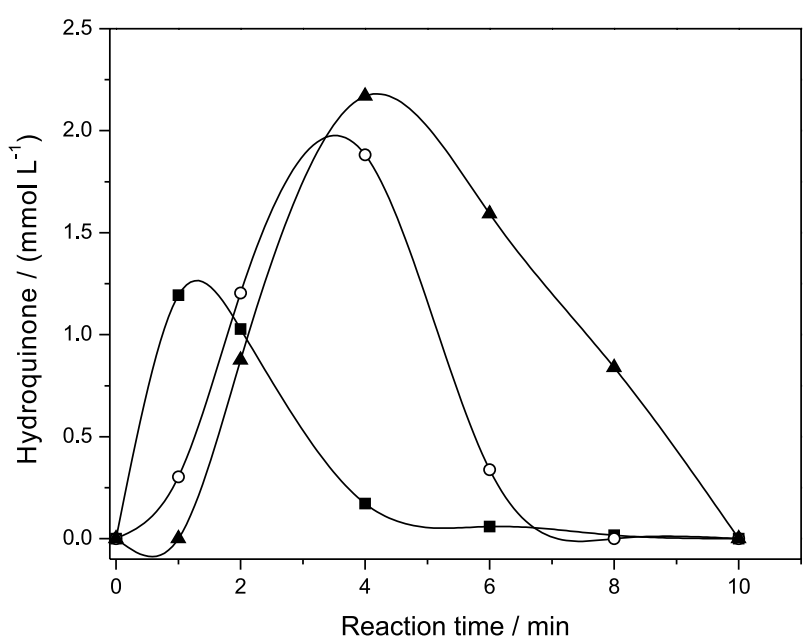

Figure 4. Formation and consumption of hydroquinone as a function of the concentration of $\mathrm{Zn}^{2+}$ added to the system. Experimental conditions: $\left[\mathrm{Fe}^{2+}\right]=0.5 \mathrm{mmol} \mathrm{L}^{-1},\left[\mathrm{H}_{2} \mathrm{O}_{2}\right]=200 \mathrm{mmol} \mathrm{L}^{-1}, \mathrm{~T}=30^{\circ} \mathrm{C}$ and $\mathrm{pH}_{\text {initial }} 3.0$; $\left[\mathrm{Zn}^{2+}\right]$ : absence $(\boldsymbol{\square}), 2 \mathrm{mmol} \mathrm{L}{ }^{-1}(\bigcirc)$ and $5 \mathrm{mmol} \mathrm{L}^{-1}(\boldsymbol{\Delta})$.

also a decrease in the formation and consumption rates of hydroquinone with increasing zinc concentration.

In these experiments, it was used 0.5 to $200 \mathrm{mmol} \mathrm{L}^{-1}$ $\mathrm{H}_{2} \mathrm{O}_{2}$. This ratio would yield a maximum of $0.5 \mathrm{mmol} \mathrm{L}^{-1}$ of hydroxyl radicals, and when all of the $\mathrm{Fe}^{2+}$ was oxidized to $\mathrm{Fe}^{3+}$, the degradation process should become slow since the reduction reaction of $\mathrm{Fe}^{3+}$ to $\mathrm{Fe}^{2+}$ by $\mathrm{H}_{2} \mathrm{O}_{2}$ is slow. As shown in Figure 2, the amount of phenol was greater than $0.5 \mathrm{mmol} \mathrm{L}^{-1}$. Therefore, there must be another process capable of recycling $\mathrm{Fe}^{3+}$ to $\mathrm{Fe}^{2+}$ with high efficiency. It is known that catechol can form a complex with $\mathrm{Fe}^{3+}$ produced by thermal Fenton reaction. This complex is capable of reducing $\mathrm{Fe}^{3+}$ to $\mathrm{Fe}^{2+}$ by an electron transfer mechanism and $\mathrm{Fe}^{2+}$ regenerated could be used again in the thermal Fenton reaction to continue the oxidation process. Therefore, there 
is an increased lifetime of the catechol after the addition of zinc ions to the system as shown in Figure 3.

According to Hamilton et al., ${ }^{7}$ the acceleration rate of hydroxylation of aromatic compounds when $\mathrm{Fe}^{2+}, \mathrm{H}_{2} \mathrm{O}_{2}$ and a dihydroxy benzeno (DHB) like catechol are present in the system is due to a ternary DHB-Fe- $\mathrm{H}_{2} \mathrm{O}_{2}$ complex, which is then the active oxidizing agent, rather than hydroxyl radicals. However, it is also known that catechol $\left(\mathrm{H}_{2} \mathrm{cat}\right)$ is able to reduce $\mathrm{Fe}^{3+}$ to $\mathrm{Fe}^{2+}$ rapidly at low $\mathrm{pH},{ }^{13,14}$ resulting in the complex $\left[\mathrm{Fe}^{2+}\left(\mathrm{cat}^{\circ}\right)\right]^{+}$, which is unstable at $\mathrm{pH}<2.0$ and dissociates to the free semiquinone radical (Hcat ${ }^{\circ}$. The disproportionation of Hcat regenerates catechol and forms $o$-benzoquinone (equations 1-3). Thus, the regeneration of $\mathrm{Fe}^{2+}$ could be responsible for the observed acceleration of the decomposition rate.

$$
\begin{aligned}
& \mathrm{Fe}^{2+}+\mathrm{H}_{2} \mathrm{cat} \rightleftarrows\left[\mathrm{Fe}^{2+}\left(\mathrm{cat}^{\bullet}\right)\right]^{+}+2 \mathrm{H}^{+} \\
& {\left[\mathrm{Fe}^{2+}\left(\mathrm{cat}^{\bullet}\right)\right]^{+}+\mathrm{H}^{+} \rightleftarrows \mathrm{Fe}^{2+}+\mathrm{Hcat}^{\bullet}}
\end{aligned}
$$

$2 \mathrm{Hcat}^{\bullet} \rightleftarrows \mathrm{H}_{2} \mathrm{cat}+o$-benzoquinone

The analysis of the organic compounds present at the end of the reaction showed principally the formation of oxalic acid (OA) (Figure 5). The ferrioxalate complex removes free $\mathrm{Fe}^{3+}$ from the solution, decreasing the efficiency of the Fenton reaction.

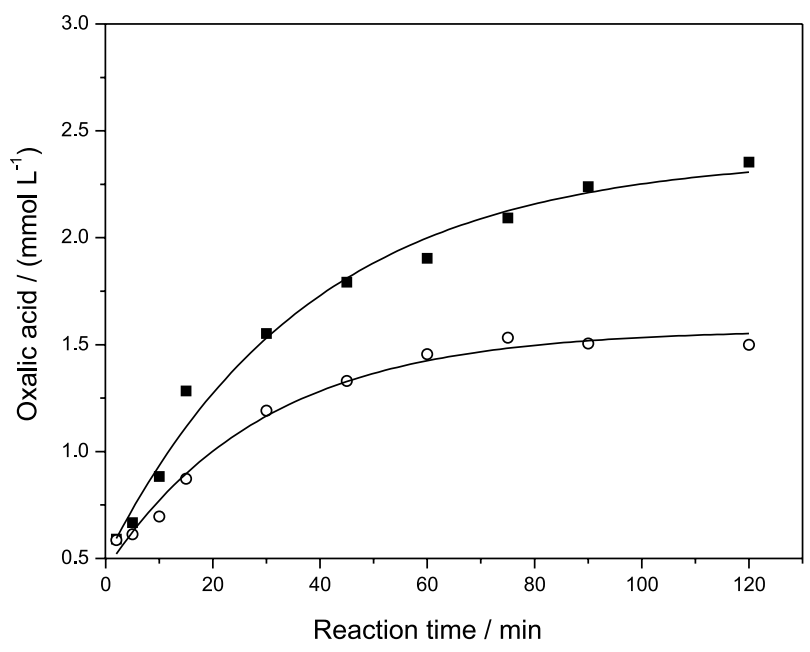

Figure 5. Variation of the concentration of oxalic acid (OA) with time. Effect of addition of inorganic ions on the degradation of $10 \mathrm{mmol} \mathrm{L}^{-1}$ phenol. Experimental conditions: $\left[\mathrm{H}_{2} \mathrm{O}_{2}\right]=200 \mathrm{mmol} \mathrm{L}^{-1}, \mathrm{~T}=30^{\circ} \mathrm{C}$ and $\mathrm{pH}_{\text {initial }}$ 3.0. Addition of ions $0.50 \mathrm{mmol} \mathrm{L}^{-1} \mathrm{Fe}^{2+}(\mathbf{\square})$ or $0.50 \mathrm{mmol} \mathrm{L}^{-1}$ $\mathrm{Fe}^{2+}+0.50 \mathrm{mmol} \mathrm{L}^{-1} \mathrm{Zn}^{2+}(\mathrm{O})$.

In EPR studies, the addition of $\mathrm{Zn}^{2+}$ is used as a technique to increase the persistence of the semiquinone radical of catechol in aqueous media. ${ }^{11,15-17}$ Therefore, if the semiquinone radical is present in the system, an effect of $\mathrm{Zn}^{2+}$ ion is expected. In fact, the addition of $\mathrm{Zn}^{2+}$ to the system increased the persistence time of catechol in the reaction medium, as shown in Figure 3.

Using phenol as substrate for degradation, it was performed a kinetic modeling of the experimental curves for the disappearance of phenol and formation and degradation of catechol and hydroquinone. The differential equations for the variation of the concentration of the species were solved by numerical integration techniques, employing the software COPASI 4.6. ${ }^{18}$

In this model, the organic reactions involving the hydroperoxyl radical were assumed to be insignificant because the dissolved oxygen was consumed in a few seconds after the start of the Fenton reaction in the absence of light. ${ }^{18}$ It was used a generic reaction for $\mathrm{H}_{2} \mathrm{O}_{2}$ production to simulate the gradual addition of this reagent during the first $60 \mathrm{~min}$ of reaction, with an addition rate of $1 \mathrm{~mL} \mathrm{~min}^{-1}$. Reactions R01 to R08, listed in Table 1, represent the main inorganic reactions in the Fenton system.

Table 1. Minimal set of inorganic reactions for the description of the Fenton reaction

\begin{tabular}{lccc}
\hline & Reaction & $k /\left(\mathrm{mmol} \mathrm{L}^{-1} \mathrm{~s}^{-1}\right)$ & Reference \\
\hline $\mathrm{R} 01$ & $\mathrm{Fe}^{2+}+\mathrm{H}_{2} \mathrm{O}_{2} \rightarrow \mathrm{Fe}^{3+}+\mathrm{HO}^{\bullet}+\mathrm{HO}^{-}$ & $k_{1}=63$ & 19 \\
$\mathrm{R} 02$ & $\mathrm{Fe}^{3+}+\mathrm{H}_{2} \mathrm{O}_{2} \rightarrow \mathrm{Fe}^{2+}+\mathrm{HO}_{2}^{\bullet}+\mathrm{H}^{+}$ & $k_{2}=0.01$ & 19 \\
$\mathrm{R} 03$ & $\mathrm{HO}+\mathrm{HO}^{\bullet} \rightarrow \mathrm{H}_{2} \mathrm{O}_{2}$ & $k_{3}=6 \times 10^{9}$ & 14 \\
$\mathrm{R} 04$ & $\mathrm{HO}+\mathrm{H}_{2} \mathrm{O}_{2} \rightarrow \mathrm{HO}_{2}^{\bullet}+\mathrm{H}_{2} \mathrm{O}$ & $k_{4}=2.7 \times 10^{7}$ & 19 \\
$\mathrm{R} 05$ & $\mathrm{HO}_{2}^{\cdot}+\mathrm{HO}_{2}^{\cdot} \rightarrow \mathrm{H}_{2} \mathrm{O}_{2}+\mathrm{O}_{2}$ & $k_{5}=8.3 \times 10^{5}$ & 20 \\
$\mathrm{R} 06$ & $\mathrm{HO}_{2}^{\bullet}+\mathrm{H}_{2} \mathrm{O}_{2} \rightarrow \mathrm{HO}^{\bullet}+\mathrm{O}_{2}+\mathrm{H}_{2} \mathrm{O}$ & $k_{6}=0.5$ & 20 \\
$\mathrm{R} 07$ & $\mathrm{Fe}^{3+}+\mathrm{HO}_{2}^{\cdot} \rightarrow \mathrm{Fe}^{2+}+\mathrm{H}^{+}+\mathrm{O}_{2}$ & $k_{7}=2 \times 10^{3}$ & 2 \\
$\mathrm{R}^{2}$ & $\mathrm{Fe}^{2+}+\mathrm{HO}_{2} \rightarrow \mathrm{Fe}^{3+}+\mathrm{H}_{2} \mathrm{O}_{2}$ & $k_{8}=1.2 \times 10^{6}$ & 2 \\
\hline
\end{tabular}

The rate constants of reactions R01 to R08 are widely known and discussed in the literature. ${ }^{2,14,19,20}$ The reaction R01 is the crucial stage of the Fenton reaction due to the formation of the hydroxyl radical, which is a strong oxidant.

The initial step involves the exchange of one water molecule of hydration of hexaaquoiron(II) by a molecule of peroxide. This complex of $\mathrm{Fe}^{2+}$ with $\mathrm{H}_{2} \mathrm{O}_{2}$ decomposes, generating the hydroxyl radical and $\mathrm{Fe}^{3+}$. Although it is possible to produce large quantities of hydroxyl radicals from reaction R01 stoichiometrically, reactions R03 and R04 efficiently consume hydroxyl radicals. Therefore, in practical applications of the Fenton reaction, catalytic amounts of iron salts (below $10^{-4} \mathrm{~mol} \mathrm{~L}^{-1}$ ) are typically used and hydrogen peroxide added slowly to the system.

The addition of the hydroxyl radical to phenol is represented by reactions R09 and R10, forming hydroxycyclohexadienyl radicals by addition of $\mathrm{HO}$ radical 
in the ortho and para positions of phenol. The meta position is less favored because the hydroxycyclohexadienyl radical formed by attack at the meta position is less stable. These radicals may undergo subsequent oxidation, reforming the $\mathrm{Fe}^{2+}$ ion. Reactions R11 and R12 form catechol and hydroquinone, respectively, and these intermediaries were identified and quantified by HPLC analysis. The proposed kinetic model for phenol oxidation consists of the ten reactions listed in Table 2 and the steps involving zinc complexation are listed in Table 3.

Table 2. Kinetic model for the initial steps of the Fenton degradation of phenol

\begin{tabular}{|c|c|c|c|}
\hline & Reaction & $k /\left(\mathrm{mmol} \mathrm{L}^{-1} \mathrm{~s}^{-1}\right)$ & Reference \\
\hline R09 & phenol $+\mathrm{HO}^{\bullet} \rightarrow o-\mathrm{DHCR}^{\bullet a}$ & $k_{9}=2 \times 10^{10}$ & 19 \\
\hline $\mathrm{R} 10$ & phenol $+\mathrm{HO}^{\bullet} \rightarrow p$ - $\mathrm{DHCR}^{\bullet b}$ & $k_{10}=1 \times 10^{10}$ & 19 \\
\hline R11 & $o-\mathrm{DHCR}^{\bullet}+\mathrm{Fe}^{3+} \rightarrow \mathrm{cat}^{\mathrm{c}}+\mathrm{Fe}^{2+}$ & $k_{1 I}=1.4 \times 10^{4}$ & 19 \\
\hline $\mathrm{R} 12$ & $p-\mathrm{DHCR}^{\bullet}+\mathrm{Fe}^{3+} \rightarrow \mathrm{hq}^{\mathrm{d}}+\mathrm{Fe}^{2+}$ & $k_{12}=7 \times 10^{3}$ & 19 \\
\hline $\mathrm{R} 13$ & $\mathrm{cat}+\mathrm{HO}^{\bullet} \rightarrow \mathrm{THCD}^{\bullet}$ & $k_{13}=1 \times 10^{10}$ & 21 \\
\hline R14 & $\mathrm{hq}+\mathrm{HO}^{\bullet} \rightarrow \mathrm{THCD}^{\bullet}$ & $k_{14}=1 \times 10^{10}$ & 21 \\
\hline R15 & $\mathrm{THCD}^{\bullet}+\mathrm{Fe}^{3+} \rightarrow \mathrm{Fe}^{2+}+\mathrm{THB}^{\mathrm{f}}$ & $k_{15}=7 \times 10^{3}$ & 19 \\
\hline R16 & $\mathrm{THB}+\mathrm{HO}^{\bullet} \rightarrow$ poliphenol & $k_{16}=2.5 \times 10^{8}$ & 20 \\
\hline R17 & polyphenol $+\mathrm{HO}^{\bullet} \rightarrow$ poliphenol$^{\bullet}$ & $k_{17}=1 \times 10^{10}$ & 20 \\
\hline $\mathrm{R} 18$ & poliphenol ${ }^{\bullet}+\mathrm{Fe}^{3+} \rightarrow \mathrm{Fe}^{2+}+$ products & $k_{18}=1 \times 10^{4}$ & 20 \\
\hline
\end{tabular}

${ }^{\mathrm{a}} o$-DHCR': ortho-dihydroxycyclohexadienyl radical; ' $p$-DHCR': para-dihydroxycyclohexadienyl radical; ${ }^{c}$ cat: catechol; ${ }^{d} \mathrm{hq}$ : hydroquinone; ${ }^{\mathrm{e}} \mathrm{THCD}$ ': trihydroxycyclohexadienyl radical; 'THB: trihydroxybenzene.

Table 3. Additional kinetic steps involving zinc complexation with the intermediate initially formed in phenol degradation

\begin{tabular}{ccc}
\hline & Reaction & $k /\left(\mathrm{mmol} \mathrm{L}^{-1} \mathrm{~s}^{-1}\right)^{\mathrm{d}}$ \\
\hline $\mathrm{R} 19$ & $o-\mathrm{DHCR}^{\bullet}+\mathrm{Zn}^{2+} \rightleftarrows \mathrm{Zn}(o-\mathrm{DHCR})^{2+\mathrm{a}}$ & $k_{19}=1 \times 10^{3}$ \\
& $k_{-19}=0.01$ \\
$\mathrm{R} 20$ & $p$ - $\mathrm{DHCR}+\mathrm{Zn}^{2+} \rightleftarrows \mathrm{Zn}(p-\mathrm{DHCR})^{2+\mathrm{b}}$ & $k_{20}=1 \times 10^{2}$ \\
& $k_{-20}=0.005$ \\
$\mathrm{R} 21$ & $\mathrm{THCD}^{\bullet}+\mathrm{Zn}^{2+} \rightleftarrows \mathrm{Zn}(\mathrm{THCD})^{2+\mathrm{c}}$ & $k_{21}=10$ \\
$\mathrm{R} 22$ & $\mathrm{Zn}(\mathrm{THCD})^{2+}+\mathrm{Fe}^{3+} \rightarrow \mathrm{Fe}^{2+}+\mathrm{THB}+\mathrm{Zn}^{2+}$ & $k_{22}=1 \times 10^{-4}$ \\
\hline
\end{tabular}

${ }^{a} \mathrm{Zn}(o-\mathrm{DHCR})^{2+}$ : zinc complex of the ortho-dihydroxycyclohexadienyl radical; ${ }^{b} \mathrm{Zn}(p-\mathrm{DHCR})^{2+}$ : zinc complex of the para-dihydroxycyclohexadienyl radical; ' $\mathrm{Zn}(\mathrm{THCD})^{2+}$ : zinc complex of the trihydroxycyclohexadienyl radical; ${ }^{\mathrm{d}}$ this work.

The reaction of $\mathrm{HO}^{\bullet}$ with the radical intermediates reduces $\mathrm{Fe}^{3+}$ to $\mathrm{Fe}^{2+}$. However, these intermediates, initially formed in the process of phenol degradation, are consumed during the Fenton reaction, possibly disrupting the iron redox cycle and stopping the reaction. The first intermediate, the $o$ - hydroxycyclohexadienyl radical $(o$-DHCR $\bullet)$, is the main intermediate that reduces the $\mathrm{Fe}^{3+}$ ion in the decomposition of phenol to form catechol. Several authors have suggested that $\mathrm{Fe}^{2+}$ is regenerated only by organic intermediates..$^{22-26}$

The kinetic model fits the decomposition of phenol by Fenton reaction and the generation and decay of the dihydroxybenzene intermediaries reasonably well, highlighting the importance of the regeneration of $\mathrm{Fe}^{2+}$ by the reaction intermediates in the degradation of phenol, as shown in Figure 6.

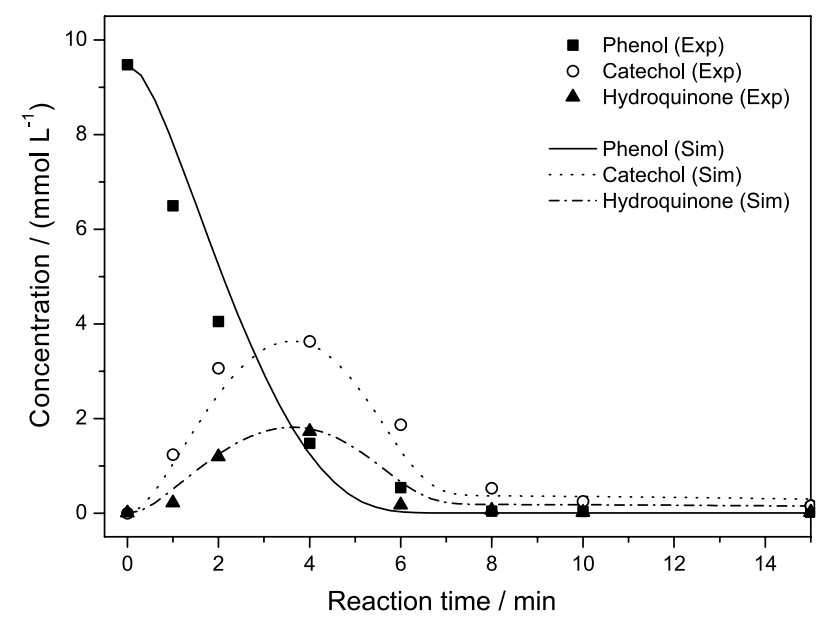

Figure 6. Comparison between the kinetic model and the experimental data for phenol degradation by the Fenton reaction in the absence of $\mathrm{Zn}^{2+}$.

The experimental results show that there is an increase in the disappearance rate of organic carbon depending on the concentration of $\mathrm{Zn}^{2+}$. Due to the increased persistence of the semiquinone radical of catechol in aqueous solution, $\mathrm{Fe}^{2+}$ is regenerated for a longer time and more $\mathrm{HO}^{\bullet}$ radicals are generated.

The kinetic modeling of the formation and consumption of catechol and hydroquinone during the phenol degradation in the presence of zinc ions required the inductions of reactions R19 and R20, which correspond to the complexation of zinc with the ortho- and paradihydroxycyclo hexadienyl radicals, respectively. Figure 7 shows the comparison between the experimental data and the simulation in the presence of zinc ions.

Figures 6 and 7 show a reasonable correlation between the modeling results and the experimental results. The difference between the curves of consumption of phenol is due to small variations in the initial concentrations of this compound, which do not affect the reaction mechanism. The reactions involving the reduction of $\mathrm{Fe}^{3+}$ by the di- and trihydroxycyclohexadienyl radicals are indispensable for the modeling process and explain the high extent of phenol degradation, considering the stoichiometry of the process. The results underscore the importance of the regeneration of $\mathrm{Fe}^{2+}$ in the degradation of organic compounds that form intermediates capable of reducing $\mathrm{Fe}^{3+}$. 


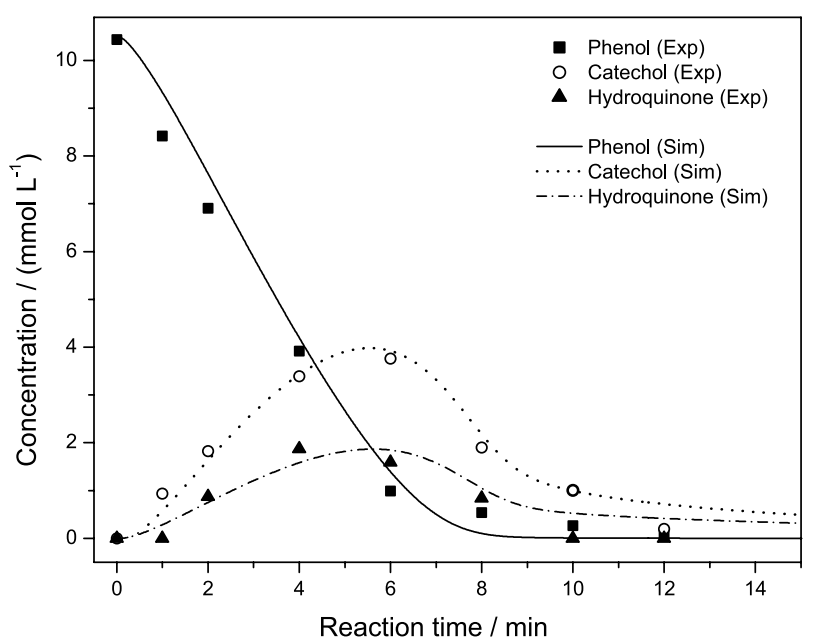

Figure 7. Comparison between experimental data and the kinetic model for phenol degradation by Fenton reaction in the presence of Zinc ions $\left(\left[\mathrm{Zn}^{2+}\right]=5 \mathrm{mmol} \mathrm{L}^{-1}\right)$.

\section{Conclusions}

This study confirms the existence of an effect of $\mathrm{Zn}^{2+}$ ion on persistence time of the formed intermediates on the phenol degradation by the Fenton reaction. Catechol, one of the main initial intermediates in the Fenton oxidation of phenol, can complex with $\mathrm{Fe}^{3+}$. This complex is capable of reducing $\mathrm{Fe}^{3+}$ to $\mathrm{Fe}^{2+}$, here by catalyzing the overall process of oxidation. In the initial stages of the Fenton reaction, the presence of zinc ions exerted a beneficial effect on the phenol degradation since it enhances the persistence of catechol, probably via stabilization of the corresponding semiquinone radical. Our results provide further indications that the reduction of $\mathrm{Fe}^{3+}$ to $\mathrm{Fe}^{2+}$ in the presence of $\mathrm{H}_{2} \mathrm{O}_{2}$ and catechol is an important catalytic pathway for the Fenton reaction in our system.

\section{Acknowledgments}

L. C. F. thanks the Conselho Nacional de Desenvolvimento Científico e Tecnológico (CNPq), Brasília, for graduate research fellowship support, and LSCP. C. L. P. S. Z. thanks FAPEAL, M. A. M. thanks ALCOA Foundation, A. M. Jr. thanks FUNDECT for financial support of the work at UFMS, V. O. S. and F. H. Q. thank the CNPq and INCT-Catalysis for fellowships and funding.

\section{References}

1. Fenton, H. J. H.; J. Chem. Soc. 1894, 65, 899.

2. Pignatello, J. J.; Oliveros, S. E.; Mackay, A.; Crit. Rev. Environ. Sci. Technol. 2006, 36, 1.
3. Walling, C.; Acc. Chem. Res. 1975, 8, 125.

4. Oliveros, E.; Legrini, O.; Hohl, M.; Müller, T.; Braun, A. M.; Water Sci. Technol. 1997, 35, 223.

5. Chen, F.; Ma, W.; He, J.; Zhao, J.; J. Phys. Chem. A. 2002, 106, 9485.

6. Du, Y.; Zhou, M.; Lei, L.; J. Hazard. Mater. 2006, 136, 859.

7. Hamilton, G. A.; Friedman, J. P.; Campbell, P. M.; J. Am. Chem. Soc. 1966a, 88, 5266.

8. Hamilton, G. A.; Hanifin Jr., J. W.; Friedman, J. P.; J. Am. Chem. Soc. 1966b, 88, 5269.

9. Bray, W. C.; Gorin, M. H.; J. Am. Chem. Soc. 1932, 54, 2124.

10. Ferrari, R. P.; Laurenti, E; Spectrochimica Acta, Part A 1993, 49, 1261.

11. Yamasaki, H.; Grace, S.; Fed. Eur. Biochem. Soc. 1998, 422, 377.

12. Machuleck Jr., A; Moraes, J. F.; Vautier-Giongo, C.; Silverio, C. A.; Friedrich, L. C.; Nascimento, C. A. O.; Gonzalez, M. C.; Quina, F. H.; Environ. Sci. Technol. 2007, 41, 8459.

13. Yoon, J.; Lee, Y.; Kim, S.; Water Sci. Technol. 2001, 44, 15.

14. Machuleck Jr., A.; Vautier-Giongo, C.; Moraes, J. E. F.; Nascimento, C. A. O.; Quina, F. H.; Photochem. Photobiol. 2006, 82, 208.

15. Shultz, D. A.; Bodnar, S. H.; Inorg. Chem. 1999, 38, 591.

16. Raju, C. L.; Gopal, N. O.; Narasimhulu, K. V.; Lakshmana, J.; Venkata, B. C.; Spectrochim. Acta, Part A 2005, 61, 2181.

17. Buszman, E.; Pilawa, B.; Zdybel, M.; Wilczynski, S.; Gondzik, A.; Witoszynska, T.; Wilczok, T.; Sci. Total Environ. 2006, 363, 195.

18. Hoops, S.; Sahle, S.; Gauges, R.; Lee, C.; Pahle, J.; Simus, N.; Singhal, M.; Xu, L.; Mendes, P.; Kummer, U.; Bioinformatics 2006, 22, 3067.

19. Kang, N.; Lee, D. S.; Yoon, J.; Chemosphere 2002, 47, 915.

20. Laat, J.; Le, T. G.; Appl. Catal., B. 2006, 66, 137.

21. Duesterberg, C. K.; Waite, T. D.; Env. Sci. Technol. 2007, 41, 4103

22. Chen, R.; Pignatello, J. J.; Env. Sci. Technol. 1997, 31, 2399.

23. Kwon, B. G.; Lee, D. S.; Kang, N.; Yoon, J. Y.; Water Res. 1999 , 33, 210.

24. Barbeni, M.; Minero, C.; Pelizzetti, E.; Chemosphere 1987, 16, 2225.

25. Mentasti, E.; Pelizzetti, E.; Saini, G.; J. Inorg. Nucl. Chem. 1976, 38, 785 .

26. Hider, R. C.; Mohd-Nor, A. R.; Silver, J.; Morrison, I. E. G.; Rees. L. V. C.; J. Chem. Soc., Dalton Trans. 1981, 609.

Submitted: November 28, 2011 Published online: June 28, 2012

FAPESP has sponsored the publication of this article. 